\title{
MODELING OF IMPACT ON MULTIPLE LAYERS WITH UNIDIRECTIONAL YARNS
} \author{
Article DOI: $\frac{\text { https://doi.org/10.35219/mtd.2018.4.01 }}{1,2}$, Laurentiu OANCEA ${ }^{1}$, Catalin PIRVU
George Ghiocel OJOC \\ Simona SANDU ${ }^{4}$, Lorena DELEANU ${ }^{1}$ \\ ${ }^{1}$ Faculty of Engineering, "Dunarea de Jos" University of Galati, Galati, Romania \\ ${ }^{2}$ Maritime University, Constanta, Romania \\ ${ }^{3}$ INCAS Bucharest, Romania \\ ${ }^{4}$ Scientific Research Center for CBRN Defense and Ecology, Bucharest, Romania \\ corresponding author: lorena.deleanu@ugal.ro
}

\begin{abstract}
The objective of this paper is to simulate the behavior of unidirectional fabrics, as realistic as possible, in order to be able to use the model in designing impact-resistant packages. There was discussed the influence of the number of layer and the impact velocity on several characteristics as residual velocity of the projectile, its acceleration and the maximum values of von Mises stresses during the impact. Three cases were considered: one layer, two layers and four layers. For all cases, the impact velocity was varied between $100 \mathrm{~m} / \mathrm{s}$ and $400 \mathrm{~m} / \mathrm{s}$, with an increment of $100 \mathrm{~m} / \mathrm{s}$, in order to simulate how the panel is damaged. The higher the impact velocity, the stressed area increases when the stress distribution is compared to the stress distribution obtained for $v_{0}=100 \mathrm{~m} / \mathrm{s}$ to that for $v_{0}=300 \mathrm{~m} / \mathrm{s}$. At the highest velocity for which the simulation was run, the stressed area has diminished. For the four layer package, for lower velocities, the residual velocity has a lower percentage of the impact velocity, but at high speeds, for this package, the reduction of the residual is even lower $\left(2.7 \%\right.$ at $v_{0}=300 \mathrm{~m} / \mathrm{s}$ and only $1.75 \%$ at $v_{0}=400 \mathrm{~m} / \mathrm{s}$ ).
\end{abstract}

Keywords: FEM model, projectile - fabrics impact, simulation, unidirectional yarns

\section{INTRODUCTION}

Ballistic protection systems can be found in a wide variety, depending on the fabric structure, but also on the nature of the material(s), the type of penetrator and impact velocity. This leads to a high degree of complexity in studying the impact processes through analytical computational methods, which has led experts in the field to solve by the help of specialized programs that use numerical methods, thus eliminating the need to perform complex equations with derivatives, which characterize the analytical models.

The researchers' efforts to save human lives in the context of their exposure to "individual attack" threats. "Modern warfare is becoming less a direct confrontation between two armies, but more and more a confrontation between two disproportionate economic and military forces, where each party tries to find new techniques to win the struggle" [1], [2].

The terrorist attacks of recent years have highlighted the need to advance and improve protection equipment as even civilians are subject to these threats.

Improving the level of protection increases the chances of success of an intervention, this having also an influence on psychological factor that can be crucial for a soldier / policeman who can focus on the life protection of innocent people.

The objective of this paper is to simulate the behavior of unidirectional fabrics, as realistic as possible, in order to be able to use the model in designing impact-resistant packages.

Yang et al. [3] developed a numerical model that takes into account both intralaminar and interlaminar damage. The intralaminar damage model is based on the CDM approach and implemented into ABAQUS by a subroutine, which includes the strain-based Hashin criteria, the exponential damage evolution law and the nonlinear shear model. The interlaminar damage is simulated by interface elements with cohesive zone model. The dominant damage processes in the laminate are matrix tensile damage and delamination, in good agreement between 
numerical and experimental results, for both the damage area and the impact force.

Rajput et al. [4] simulated the impact of a $9 \mathrm{~mm}$ full-jacketed bullet with a striking velocity of $358 \mathrm{~m} / \mathrm{s}$ on a KEVLAR helmet, using finite element method, implemented through Ansys AUTODYN-3D.

Sockalingam et al. [5] modelled the impact of an aramid fiber with a projectile and their results indicated the need for a full 3D fiber-level model to accurately predict the impact response of the fiber. In addition to longitudinal tensile fiber properties, the fiber response is dependent on the axial compressive, transverse compressive and longitudinal shear properties of the fiber. The breaking speed depends on the projectile shape, material model behavior and boundary conditions.

For the model in [2], the yarn is included in a polymeric matrix (for instance, in some aramid fabrics, woven or unidirectional, the polyethylene is used as a thin foil to protected it, but also to keep them toghether). Literature gave simualtion of woven frabrics under impact [6], [7], [8]. For this type of flexible panels for ballistic protection, thermoplastic polymers are used, but for other applications (like helmets [9], [10] or vehicle armors [11], [12], the matrix is rigid.

\section{THE MODEL}

\subsection{The material models}

The hyposesis of the model being isothermal is accepted. In the available literature, many models are designed as isothermal systems, at least for impact velocities close to that taking into account in this model (till $400 \mathrm{~m} / \mathrm{s}$ ) as the energy transformed into heat during the impact is not significant for modifying the fibres behavior [13]. Other greater impact velocities need experiments with thermal field monitoring in order to verify if thermal energy is significant in the impact process [14].

This model considers the yarn made of one material: the yarn and its coating of polyethylene. Actually, the yarn is formed by hundreds or even thousands of fibers, but, as one may notice in Fig. 3, this model of the yarn is deformed and broken in the similar way as one fiber is.

The models for the behavior of the involved materials are presented in Tables 1 to 4 . These are selected from ([15], [16], [17], [18], [19], [20]):

- for a yarn: failure criterium: maximum equivalent plastic strain: 0.1 , the constitutive model is based on bilinear isotropic hardening form,

- the constitutive model for the lead alloy for the bullet core introduces Steinberg Guinan strength,

- the constitutive model for the copper alloy for the bullet jacket is a multilinear isotropic hardening one.

The model contains a symmetry plane passing through the axes of the bullet/yarn in the xy plane (Fig. 4b and Fig. 5). Reducing the model in half creates the hypothesis of a symmetry towards this plan, plausible in this case and it will considerably reduce the running time.

The fabric model considers the properties of the aramid fiber, as presented in the literature, but at a meso level. A layer is made of 15 separate yarns that have the same orientation. The layers were placed perpendicularly to the direction of the previos layer $\left(0^{\circ}, 90^{\circ}, 0^{\circ}, 90^{\circ}\right)$.

Table 3. Model for the copper alloy

\begin{tabular}{|c|c|}
\hline Stress, MPa & Plastic strain, $\mathbf{~ m m} / \mathbf{m m}$ \\
\hline 120 & 0 \\
\hline 450 & 0.3 \\
\hline 450 & $1 \times 10^{20}$ \\
\hline
\end{tabular}

Table 1. Mechanical characteristics of the involved materials

\begin{tabular}{|c|c|c|c|c|c|c|c|}
\hline Material & $\begin{array}{c}\text { Density } \\
\mathbf{k g} / \mathbf{m}^{\mathbf{3}}\end{array}$ & $\begin{array}{c}\text { Young } \\
\text { modulus, } \\
\text { MPa }\end{array}$ & $\begin{array}{c}\text { Poisson } \\
\text { Coefficient }\end{array}$ & $\begin{array}{c}\text { Isostatic } \\
\text { modulus of } \\
\text { elasticity, } \\
\text { MPa }\end{array}$ & $\begin{array}{c}\text { Shear } \\
\text { modulus, } \\
\text { MPa }\end{array}$ & $\begin{array}{c}\text { Yield limit } \\
\text { in } \\
\text { traction, } \\
\text { MPa }\end{array}$ & $\begin{array}{c}\text { Tangent } \\
\text { modulus, } \\
\text { MPa }\end{array}$ \\
\hline Yarn & $1.44 \times 10^{3}$ & 65000 & 0.35 & 72222 & 24074 & 630 & 1900 \\
\hline Copper alloy & $8.9 \times 10^{3}$ & $1.1 \times 10^{5}$ & 0.34 & $1.14 \times 10^{11}$ & 46400 & 280 & $1.15 \times 10^{9}$ \\
\hline Lead alloy & $11.34 \times 10^{3}$ & $1.6 \times 10^{4}$ & 0.3 & $4.44 \times 10^{10}$ & 8600 & 30 & $1.1 \times 10^{8}$ \\
\hline
\end{tabular}

Table 2. Material constant in skock EOS linear (similar to [19], [20], but isotropic)

\begin{tabular}{|l|c|c|c|c|}
\hline \multicolumn{1}{|c|}{ Material } & Gruneisen coefficient & $\begin{array}{c}\mathbf{C 1} \\
\mathbf{m m} / \mathbf{s}\end{array}$ & $\mathbf{S 1}$ & $\begin{array}{c}\text { Quadratic parameter, } \\
\mathbf{m m} / \mathbf{s}\end{array}$ \\
\hline Lead & 2.64 & $2.006 \times 10^{6}$ & 1.429 & 0 \\
\hline Copper alloy & 2 & $3.958 \times 10^{6}$ & 1.497 & 0 \\
\hline
\end{tabular}

Table 4. Model for the lead alloy the core is made of

\begin{tabular}{|c|c|c|c|c|c|c|c|}
\hline $\begin{array}{c}\text { Initial } \\
\text { yield } \\
\text { stress, } \\
\text { Y, MPa }\end{array}$ & $\begin{array}{c}\text { Maximum } \\
\text { yield stress, } \\
\text { Ymax, } \\
\text { MPa }\end{array}$ & $\begin{array}{c}\text { Hardening } \\
\text { constant B }\end{array}$ & $\begin{array}{c}\text { Hardening } \\
\text { exponent } \mathbf{n}\end{array}$ & $\begin{array}{c}\text { Derivative } \\
\mathbf{d G / d P} \\
\mathbf{G}^{\prime} \mathbf{P}\end{array}$ & $\begin{array}{c}\text { Derivative } \\
\mathbf{d G} / \mathbf{d T} \\
\mathbf{G} \text { 'T } \\
\mathbf{M P a} /{ }^{\circ} \mathbf{C}\end{array}$ & $\begin{array}{c}\text { Derivative } \\
\text { dY/dP Y'P }\end{array}$ & $\begin{array}{c}\text { Melting } \\
\text { temperature, } \\
\mathbf{T m e l t}^{\circ} \mathbf{C}\end{array}$ \\
\hline 8 & 100 & 110 & 0.52 & 1 & -9.976 & $9.3 \times 10^{-4}$ & 486.85 \\
\hline
\end{tabular}




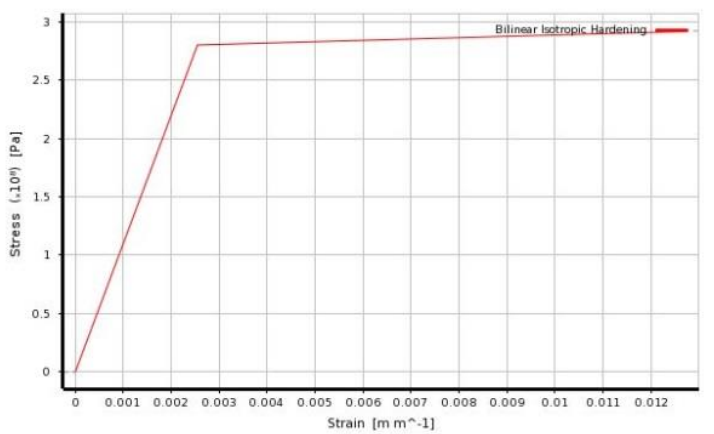

a). Bilinear isotropic hardening model for the copper alloy

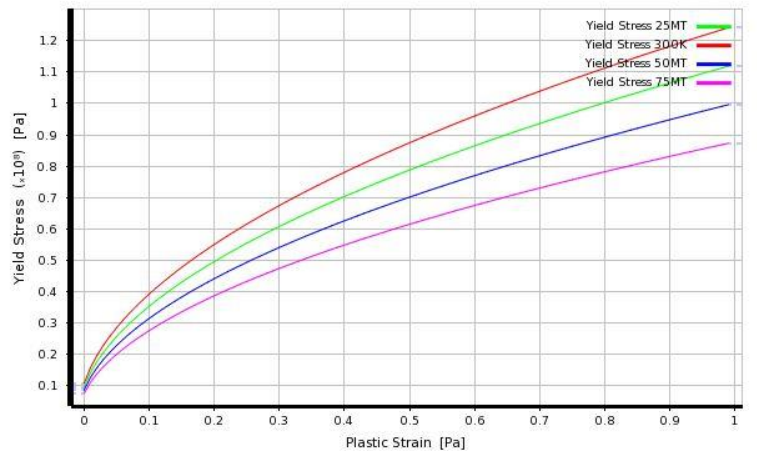

b) The constitutive model for the lead alloy the bullet core is made of

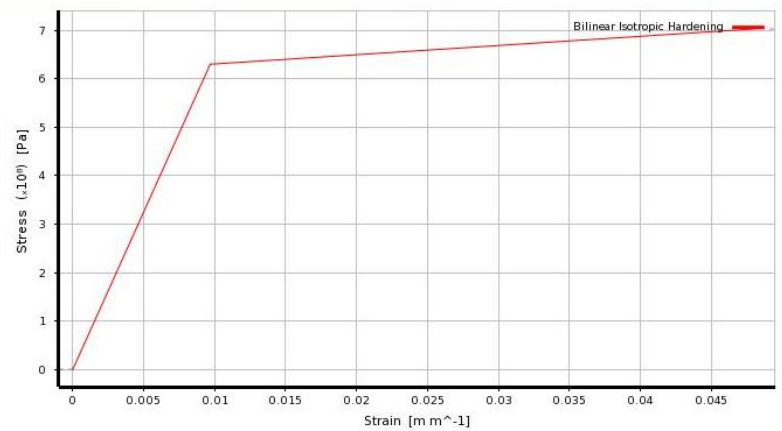

c) The constitutive model for the yarn

Fig. 1. Material models

The shape of yarn section was chosen after consulting the literature and catalogs of the manufacturers of such fabrics [21]. It could be taken as an ellipse [22], [23], [24].

For the yarn 3D model, The cross section (Fig. 2b) dimensions are $2 \mathrm{~mm} \times 0.4 \mathrm{~mm} \times 19 \mathrm{~mm}$. Section shapes were chosen to reproduce the section of an aramid yarn (Fig. 2).

The layer is built from 15 unidirectional yarns. The yarns are not fixed to each other by a polymeric foil or matrix. Friction between yarns is considered, representing a step forward in modeling, which is only considered in recent years [6].

In this study, there was considered:

- friction among yarns $\mathrm{COF}=0.4$,

- friction between yarn and projectile $\mathrm{COF}=0.3$.

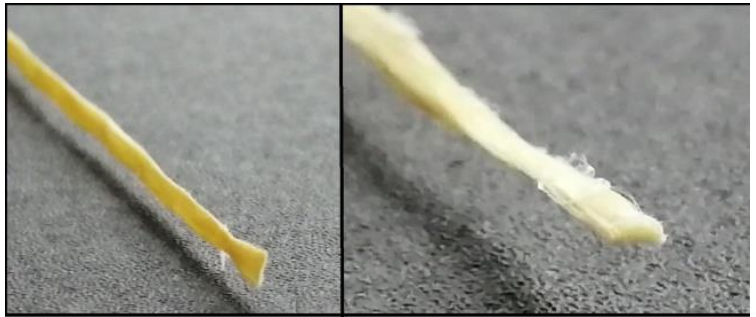

a) Aramid fiber extracted from the unidirectionalfabric

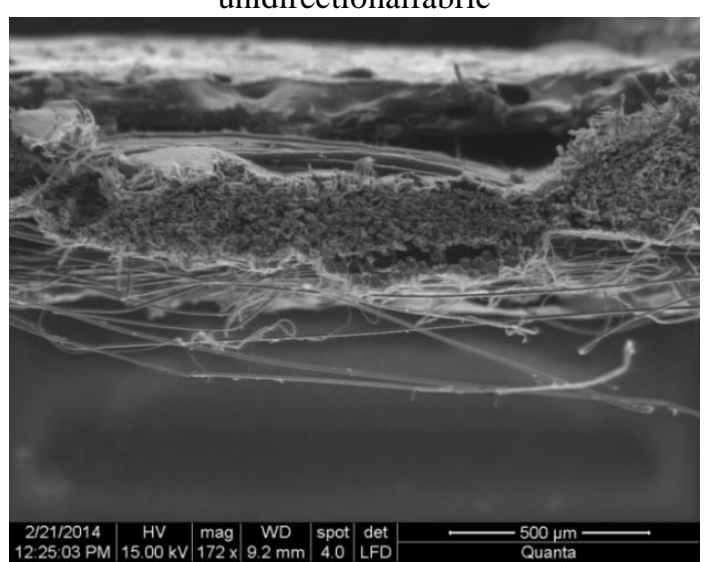

b)

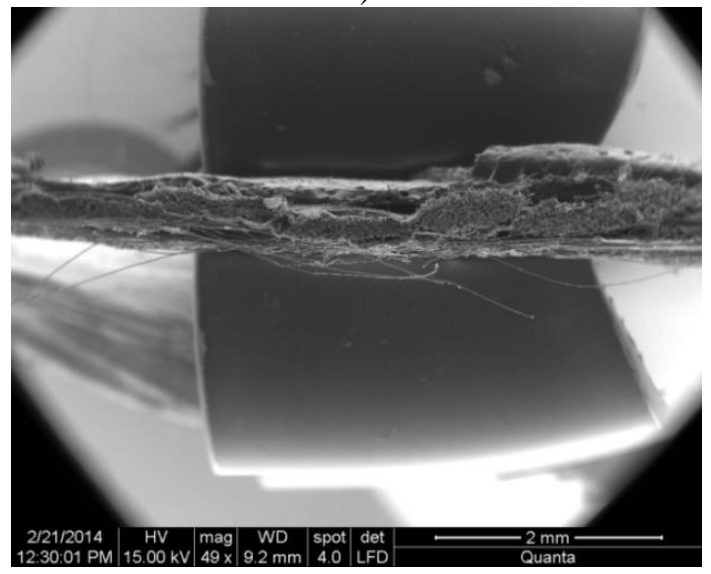

c)

Fig. 2. The shape of the yarn: a) the model for this study, b) and c) SEM images of a unidirectional

fabrics $\left(0^{\circ}, 90^{\circ}\right)$, made of aramid fibers, from Teijin [25]

The projectile is a $9 \mathrm{~mm}$ FMJ bullet. It is made of two parts, the copper outer jacket that provides rigidity and the lead core. The material properties are given in Tables 1 to 4 .

In Figure $4 a$, one can see the shape and design of a $9 \mathrm{~mm}$ MFJ bullet and Figure $4 \mathrm{~b}$ presents the 3D model of the bullet. This simplification was accepted on the basis of an analysis that the authors have done as the hardwere they used does not support a model that have the mesh finer that the actual thickness of the bullet jacket or the foil that cover the unidirectional yarn fabrics. On the other hand, this foil does not have high mechanical characteristics (medium or low density polyethylene, informative tensile limit $30 \mathrm{MPa}$ as a low density polyethylene). 
Due to the fact that the jacket of the bullet has a very small thickness as compared to its core, problems arise in the moment when the mesh generation is designed, a very fine meshing resulting in very high processing times.

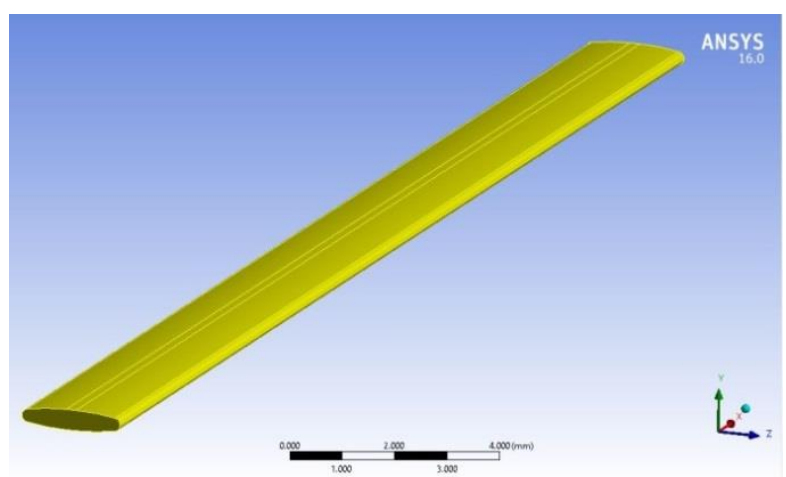

a) the yarn model

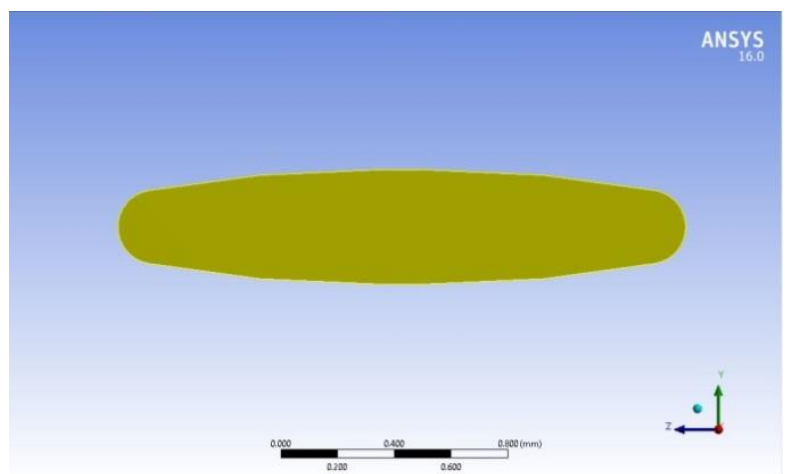

b) the cross section of the yarn

Fig. 3. The model of the yarn

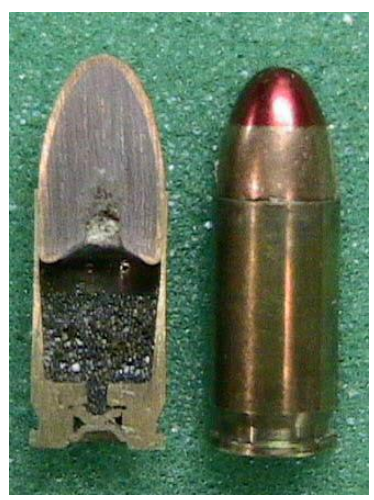

a) Projectile with 9 FMJ

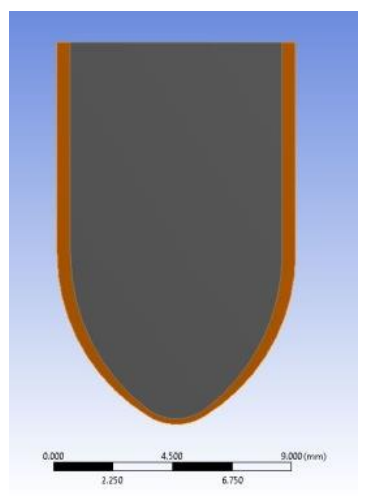

b) the model
Fig. 4. The 9 FMJ bullet

Because of this and considering the computer resources the authors worked on, the bullet shield is thicker and, therefore, more rigid than the actual one, but the projectile model is sufficiently close to reality. Many authors still consider the projectile to be rigid because they are only interested in the failure of the target [26], this approach may be allowed for modeling the impact at medium speeds $(100-400 \mathrm{~m} / \mathrm{s})$.

\subsection{The cases}

These simulations were run with the help of Ansys Explicit Dynamics, taking into account [27].

The effect of increasing the number of layers in a uniderectional fabric was analyzed. Three cases were considered: one layer, two layers and four layers. For all these cases, the impact velocity was varied between $100 \mathrm{~m} / \mathrm{s}$ and $400 \mathrm{~m} / \mathrm{s}$, with an increment of $100 \mathrm{~m} / \mathrm{s}$, in order to understand how the panel fails.

All the analyzed cases were simulated in the isothermal regime considering the works [26], [13], for which the thermal distribution, obtained with similar projectiles and speed regimes, the influence of a small thermal gradient is weak (varying several degrees to $10-20{ }^{\circ} \mathrm{C}$ ).

The contact conditions include the followings:

- the contact between the copper alloy jacket and the lead core is perfectly bonded,

- contact between yarns and bullet is with friction; the coefficient of friction was considered to be constant and equal to 0.4 .

- also, the friction coefficient between two yarns was taken 0.4.

Boundary conditions considered the yarns of the fabric fixed on the surfaces of their ends. Many authors consider that when modeling the yarn, the plate or the composite package fixed on the edges [28].

The initial conditions refer to:

- the initial bullet velocity of: $100 \mathrm{~m} / \mathrm{s}, 200 \mathrm{~m} / \mathrm{s}$, $300 \mathrm{~m} / \mathrm{s}$ and $400 \mathrm{~m} / \mathrm{s}$, respectively,

- the panel formed by 1 layer (Case 1), 2 layers $\left(0^{\circ}, 90^{\circ}\right)($ Case 2$)$ and 4 layers $\left(0^{\circ}, 90^{\circ}, 0^{\circ}, 90^{\circ}\right)$ (Case $3)$, respectively.

\subsection{Meshing}

The meshing of such models raises problems due to the very different dimensions of the solids that interact. In this case, the yarn has a much larger dimension on its axis (length) and similar dimensions, much much smaller, on the other two axes. The bullet is much larger than the crosssectional dimensions of the yarn. Figure 6 shows the mesh network for the four-layer unidirectional fabric model, for the impact bullet. For yarn meshing, a 0.2 $\mathrm{mm}$ element size was imposed. For more accurate results, the same size of the elements on the surface of the bullet tip were added.

Table 6. Model of impact between a bullet and a unidirectional fiber package

\begin{tabular}{|l|c|c|}
\hline Body & $\begin{array}{c}\text { Number of } \\
\text { nodes }\end{array}$ & $\begin{array}{c}\text { Number of } \\
\text { elements }\end{array}$ \\
\hline Jacket & 1215 & 3401 \\
\hline Core & 1420 & 6082 \\
\hline Bullet (jacket+core) & 2335 & 9483 \\
\hline Yarn & 2869 & 1650 \\
\hline One layer & 36693 & 22650 \\
\hline Two layers & 73173 & 45150 \\
\hline Four layers & 146346 & 90300 \\
\hline
\end{tabular}




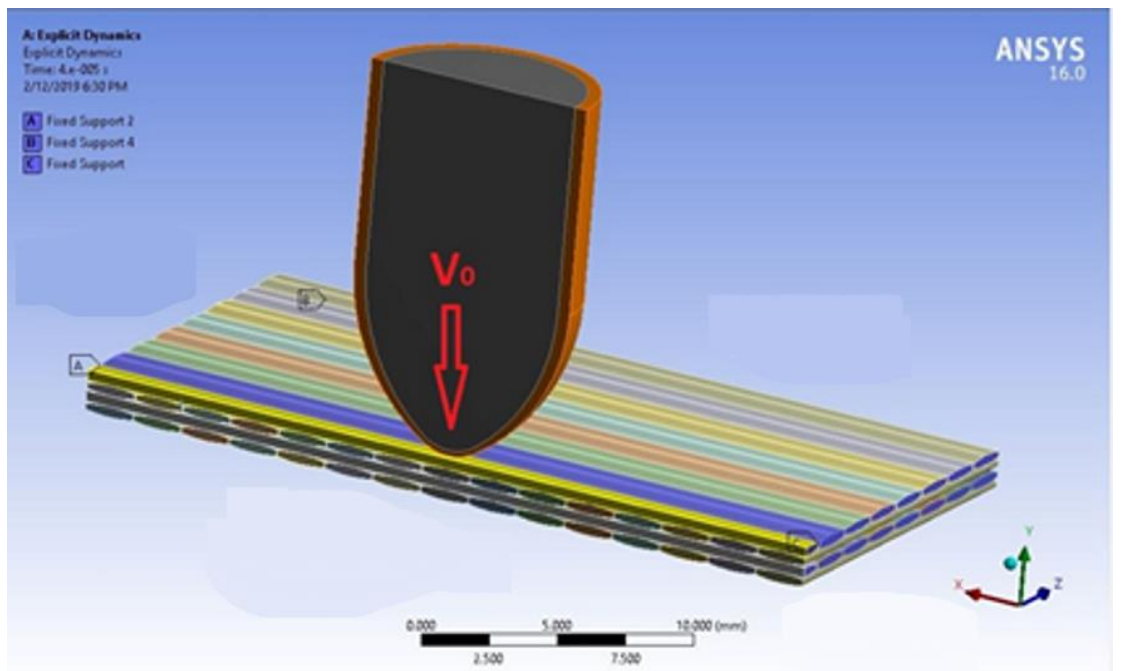

Fig. 5. Case 3. Impact between the bullet and a panel made of four layers $\left(0^{\circ}, 90^{\circ}, 0^{\circ}, 90^{\circ}\right)$.

The simulation was run in LS-Dyna. The issue of the time interval of running the action of the projectile on the target having the following aspects From specialized literature [29], [30], there have been noticed the following trends due to the increasing performances of computers:

- increasing the studied interval from a few milliseconds to $10^{-4} \mathrm{~s}$,

- a better discretization of the time interval, meaning time steps of $10^{-5} \mathrm{~s} \ldots 10^{-7} \mathrm{~s}$,

- modeling the materials in an increasingly complex form, but more appropriate to their actual behavior at high impact velocities, implicitly to their high strain rates,

- considering the anisotropic nature of materials and yarns.

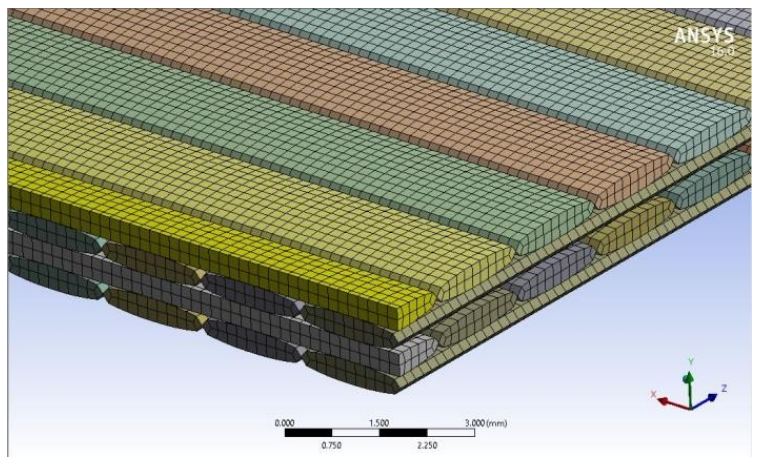

Fig. 6. Detail of a mesh network for the four-layer unidirectional fabric model
Taking into a ccount the increasing degree of complexity, from one-layer case to the four-layer case, the simulations were run over a range of no more than $10^{-4} \mathrm{~s}$, but there was enough time for the projectile to pass through the target, so the residual velocity could be determined.

\section{RESULTS AND DISCUSSIONS}

These simulations will point out the sequences in yarns failure and the differences in values of time moments of yarn breakage, the influence of number of layers and impact velocity $(100 \mathrm{~m} / \mathrm{s} \ldots 400 \mathrm{~m} / \mathrm{s})$ on the residual speed, acceleration and the failure characterization (location, number of broken yarns).

\section{Case 1. The system one layer - projectile}

Table 7 presents the moments of the first broken yarn on a fabrics with one layer, as it is noticed on simulations. The brakage of the yarn(s) are closer to the initial moment of contact $(\mathrm{t}=0)$, when the projectile is just touching the fabric.

Figure 7 presents comparatively a moment of simulations $\left(\mathrm{t}=2 \times 10^{-6} \mathrm{~s}\right)$, closer to zero moment (when the target is not yet reached). The impact velocity influences the affected area on the target, the value of equivalent stress. At $\mathrm{v}_{0}=100 \mathrm{~m} / \mathrm{s}$, the maximum equivalent stress is $663 \mathrm{MPa}$ and the stressed area is small.

Table 7. Analysis of Case 1

\begin{tabular}{|l|l|l|l|}
\hline Case & \multicolumn{1}{|c|}{$\begin{array}{c}\text { Impact } \\
\text { velocity }[\mathbf{m} / \mathbf{s}]\end{array}$} & $\begin{array}{c}\text { The moment for } \\
\text { the first yarn } \\
\text { breakage }\end{array}$ & \multicolumn{1}{c|}{ Position of the broken yarns } \\
\hline 1 & 100 & $\mathrm{t}=1.2 \times 10^{-5} \mathrm{~s}$ & yarn broken under the projectile, in one area, three broken yarns \\
\hline 2 & 200 & $\mathrm{t}=4 \times 10^{-6} \mathrm{~s}$ & yarn broken under the projectile, in one area, two broken yarns \\
\hline 3 & 300 & $\mathrm{t}=2 \times 10^{-6} \mathrm{~s}$ & $\begin{array}{l}\text { yarn broken under the projectile, in two points situated in the } \\
\text { left and in the right side of the projectile, two broken yarns }\end{array}$ \\
\hline 4 & 400 & $\mathrm{t}=2 \times 10^{-6} \mathrm{~s}$ & $\begin{array}{l}\text { yarn broken under the projectile, in two points situated in the } \\
\text { left and in the right of the projectile, two broken yarns }\end{array}$ \\
\hline
\end{tabular}



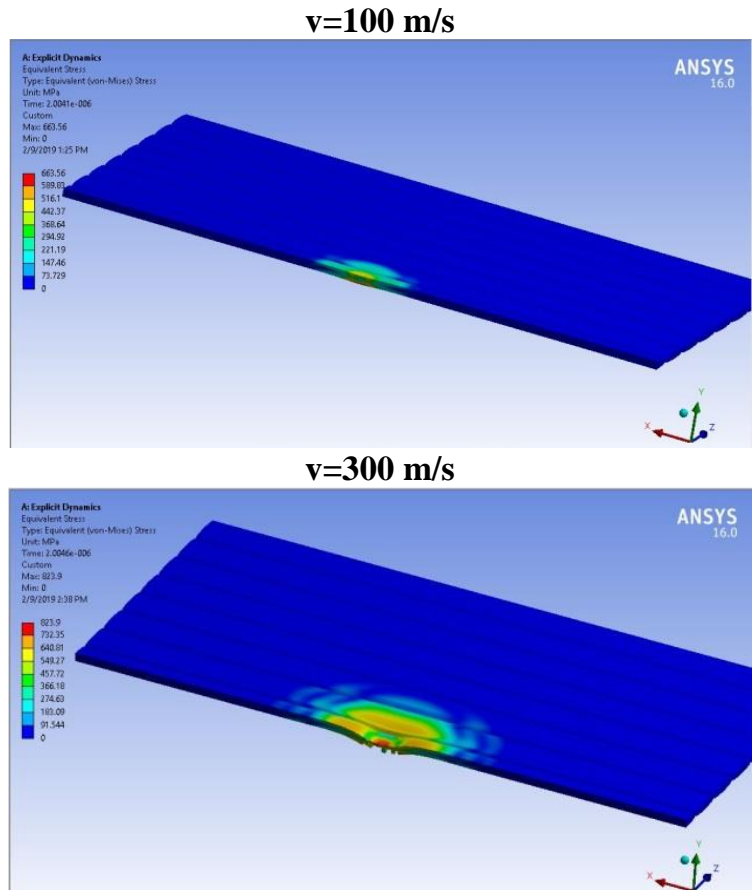
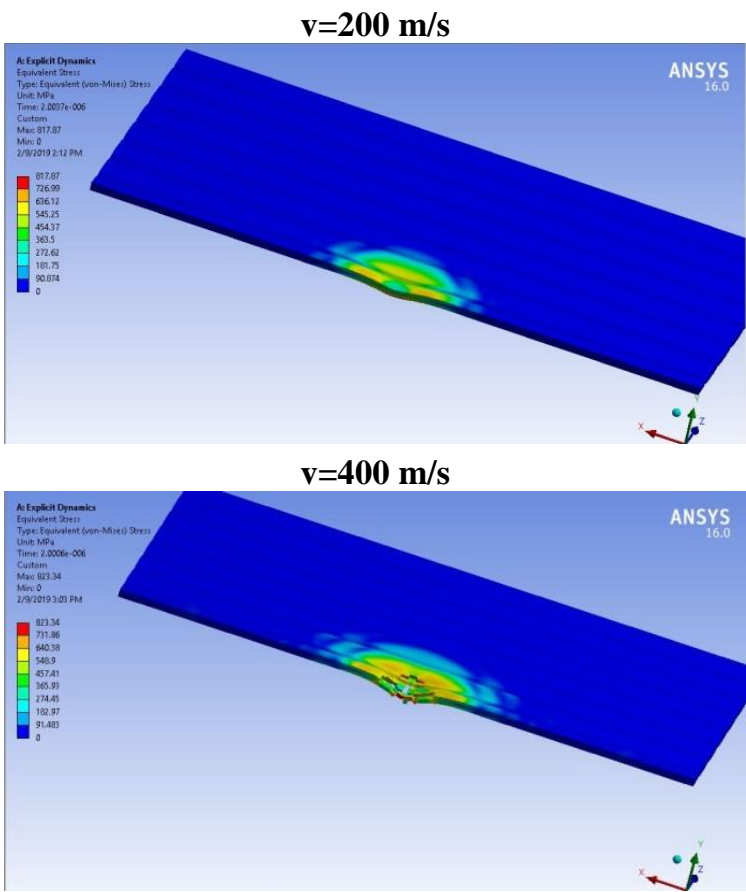

Fig. 7. The von Mises stress distribution for one layer with unidirectional fibers, at time moment $t=2 \times 10^{-6} \mathrm{~s}$

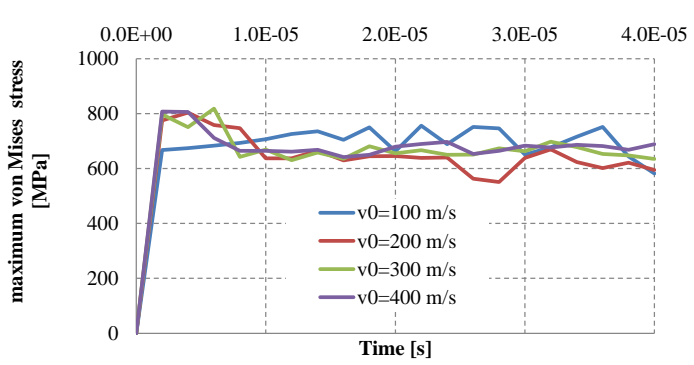

a) Maximum value of von Mises stress

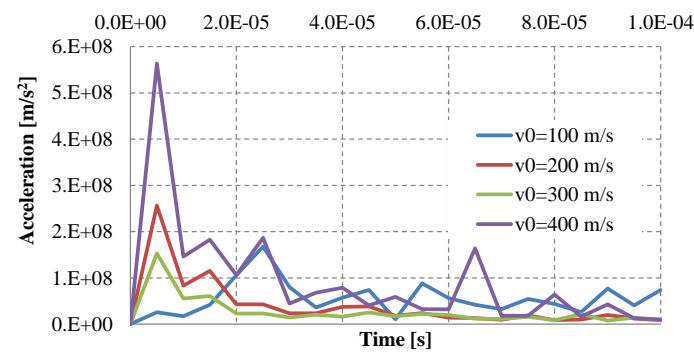

b) Accelaration of the projectile top point

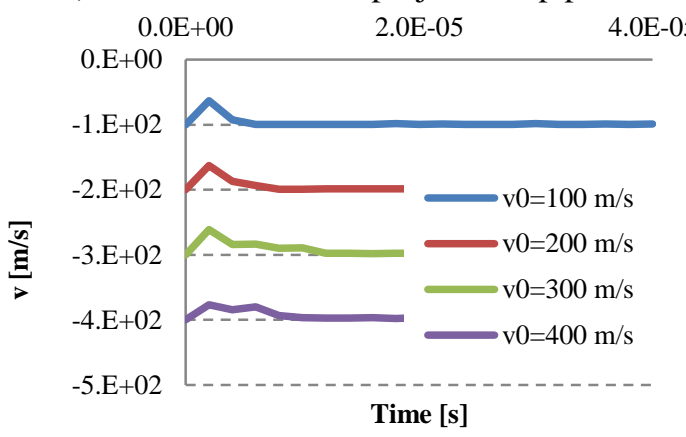

c) Velocityof the projectile top point

Fig. 8. Analysis of several characteristic parameter for impact on one layer
At $\mathrm{v}_{0}=200 \mathrm{~m} / \mathrm{s}$, the equivalent stress is $817 \mathrm{MPa}$, close to tensile limit as considered for the yarn material. At $\mathrm{v}_{0}=300 \mathrm{~m} / \mathrm{s}$, the central main yarn has already been broken, the von Mises stress reaching $823 \mathrm{MPa}$. For the highest impact velocity for which the impact with 1 layer $\left(\mathrm{v}_{0}=400 \mathrm{~m} / \mathrm{s}\right)$ was simulated, at this time moment, the main yard is broken and the adjacent yards are also partially damaged. There is a change in the stressed area of the fabric, the size of which is influenced by the magnitude of impact velocity. However, there is no clear tendency for the size and stress gradients of this area to depend on the impact velocity.

The higher the impact velocity, the stressed area increases as the stress distribution is compared to the stress distribution obtained for $\mathrm{v}_{0}=100 \mathrm{~m} / \mathrm{s}$ to that for $\mathrm{v}_{0}=300 \mathrm{~m} / \mathrm{s}$. At the highest velocity for which the simulation was run, the stressed area has diminished.

\subsection{Case 2: two layers $\left(0^{\circ}, 90^{\circ}\right)$}

The moment of breaking the two-layer fabrics $\left(0^{\circ}, 90^{\circ}\right)$, as noticed on the simulations, is given in Table 3. The authors find that the breakage of fabrics starts at a moment closer to the moment $\mathrm{t}=0$, that is, when the projectile touches the yarn without loading it.

For a package of two layers of unidirectional yarns, perpendicularly oriented $\left(0^{\circ}, 90^{\circ}\right)$, the occurrence of the first crack in the yarn(s) occur(s) at a moment closer to the impact initiation. It is noticed that the rupture is asymmetric, as it is for the actual case (see Fig. 11). Thus, for $\mathrm{v}_{0}=100 \mathrm{~m} / \mathrm{s}$, the rupture was observed on the simulation at time $\mathrm{t}=2.6 \times 10^{-5} \mathrm{~s}$, the stressed area of the panel being extended to the fixed edges. 


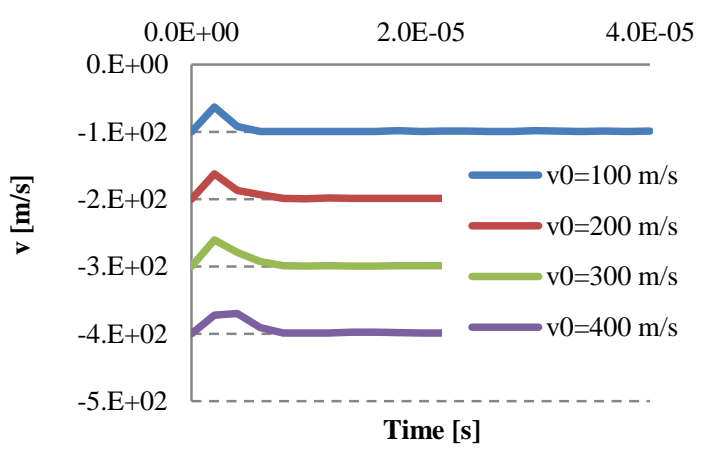

a) Velocityof the projectile top point

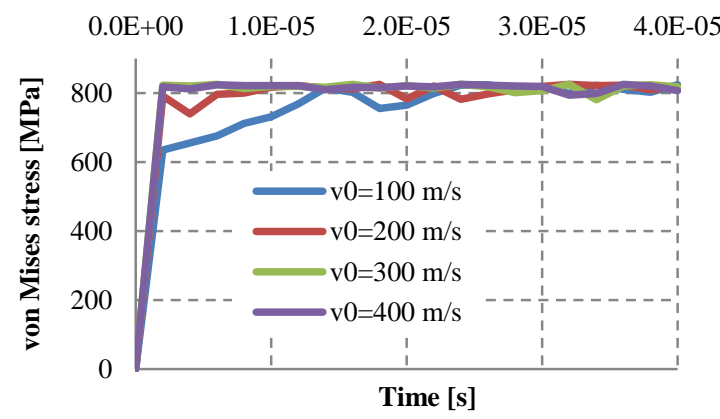

b) Maximum value of von Mises stress $\begin{array}{rrr}0.0 \mathrm{E}+00 & 5.0 \mathrm{E}-05 & 1.0 \mathrm{E}-04\end{array}$

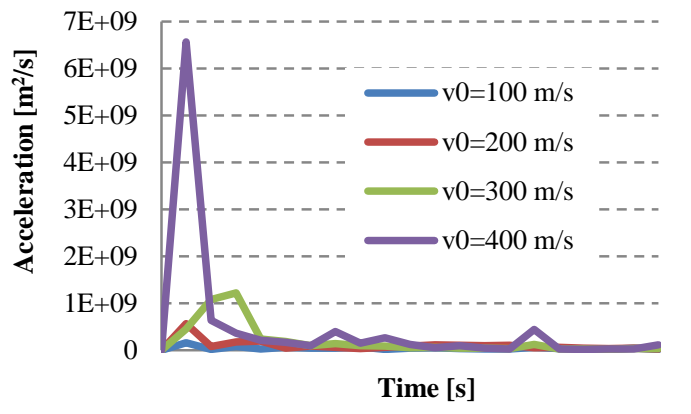

c) Accelaration of the projectile top point

Fig. 10. Analysis of several characteristics for the impact on two-layer package

The central yarn is broken and the stress concentration appears on the yarns next to it. For $\mathrm{v}_{0}=200 \mathrm{~m} / \mathrm{s}$, the yarn breakage clearly occurs in the lateral impact areas, the break initiates on the back yarn due to the relatively large strains occurring there. The stressed area has substantially decreased. At $\mathrm{v}_{0}=300 \mathrm{~m} / \mathrm{s}$, this area narrows more and the moment of the first crack in the yarn is at $t=2 \times 10^{-6} \mathrm{~s}$, much closer to the zero moment, as it also happens for the impact velocity $\mathrm{v}_{0}=400 \mathrm{~m} / \mathrm{s}$. The difference could be done more precisely if the simulation time step and the meshing elements decrease, which would involve more efficient hardware resources.

\section{Case 3. System with 4 layers with unidirectional yarns $\left(0^{\circ}, 90^{\circ}, 0^{\circ}, 90^{\circ}\right)$}

The breaking time of the four layer fabrics $\left(0^{\circ}\right.$, $\left.90^{\circ}, 0^{\circ}, 90^{\circ}\right)$, as noted from the simulations, is given in Table 3. The breakage of the yarns start at moments closer to the moment $\mathrm{t}=0$.

With the increase in the number of layers, the moment of the first crack in yarns deviates from the zero point. At lower speeds $\left(\mathrm{v}_{0}=100 \mathrm{~m} / \mathrm{s}\right.$ and $\mathrm{v}_{0}=200$ $\mathrm{m} / \mathrm{s}$ ), the stressed area is expanded, at maximum levels of $350 \mathrm{MPa}$..600 $\mathrm{MPa}$, but for the other two simulation cases $\left(\mathrm{v}_{0}=300 \mathrm{~m} / \mathrm{s}\right.$ and $\left.\mathrm{v}_{0}=400 \mathrm{~m} / \mathrm{s}\right)$, the stressed areas are much smaller. Package deformation is high at low velocities and much smaller for higher impact velocities.

The equivalent stress in the hole package may be analyzed on Fig. 11. One may notice that the package is stressed in a very short time interval $\left(0.5 \times 10^{-5} \mathrm{~s}\right)$. The shape of the graph is similar for higher velocities, but for $\mathrm{v}_{0}=100 \mathrm{~m} / \mathrm{s}$, the loading is slower and the curve has several segments with different slopes.

The velocity graphs of the projectile top reflect the mode of successive failures of the layers. As the impact velocity increases, its peaks narrow, meaning, on these graphs, that the residual velocity can be determined, this value being written on each graph.

The small variation in maximum values of the equivalent stress at the evaluated moments shows that, during the impact, high values of stress, close to the breaking limit, continuously occur in different places where the yarn or yarns initiate the damage.

Table 9. Analysis of two layer package

\begin{tabular}{|c|c|c|c|c|}
\hline Case 2 & $\mathbf{1}$ & $\mathbf{2}$ & $\mathbf{3}$ & $\mathbf{4}$ \\
\hline $\begin{array}{c}\text { Impact } \\
\text { velocity [m/s] }\end{array}$ & 100 & 200 & 300 & 400 \\
\hline $\begin{array}{c}\text { The moment } \\
\text { of first crack } \\
\text { in yarn(s), [s] }\end{array}$ & $3.5 \times 10^{-5}$ & $9 \times 10^{-6}$ & $2 \times 10^{-6}$ & $2 \times 10^{-6}$ \\
\hline
\end{tabular}

Tabelul 8. Analysis of Case 2

\begin{tabular}{|l|l|l|l|}
\hline Case & $\begin{array}{l}\text { Impact } \\
\text { velocity } \\
{[\mathbf{m} / \mathbf{s}]}\end{array}$ & $\begin{array}{l}\text { The moment for } \\
\text { the first yarn } \\
\text { breakage }\end{array}$ & \\
\hline 1 & 100 & $\mathrm{t}=2.6 \times 10^{-5} \mathrm{~s}$ & $\begin{array}{l}\text { Position of the broken yarns } \\
\text { breakage under the projectile, three broken yarns on the first layer, } \\
\text { three broken yarns on the second layer }\end{array}$ \\
\hline 2 & 200 & $\mathrm{t}=8 \times 10^{-6} \mathrm{~s}$ & $\begin{array}{l}\text { breakage under the projectile, two entirely broken yarns on the first } \\
\text { layer and one yarn with partial failure, three broken yarns on the } \\
\text { second layer }\end{array}$ \\
\hline 3 & 300 & $\mathrm{t}=2 \times 10^{-6} \mathrm{~s}$ & $\begin{array}{l}\text { breakage under the projectile, two entirely broken yarns on the first } \\
\text { layer, five broken yarns on the second layer }\end{array}$ \\
\hline 4 & 400 & $\mathrm{t}=2 \times 10^{-6} \mathrm{~s}$ & $\begin{array}{l}\text { breakage under the projectile, two entirely broken yarns on the first } \\
\text { layer, five broken yarns on the second layer }\end{array}$ \\
\hline
\end{tabular}



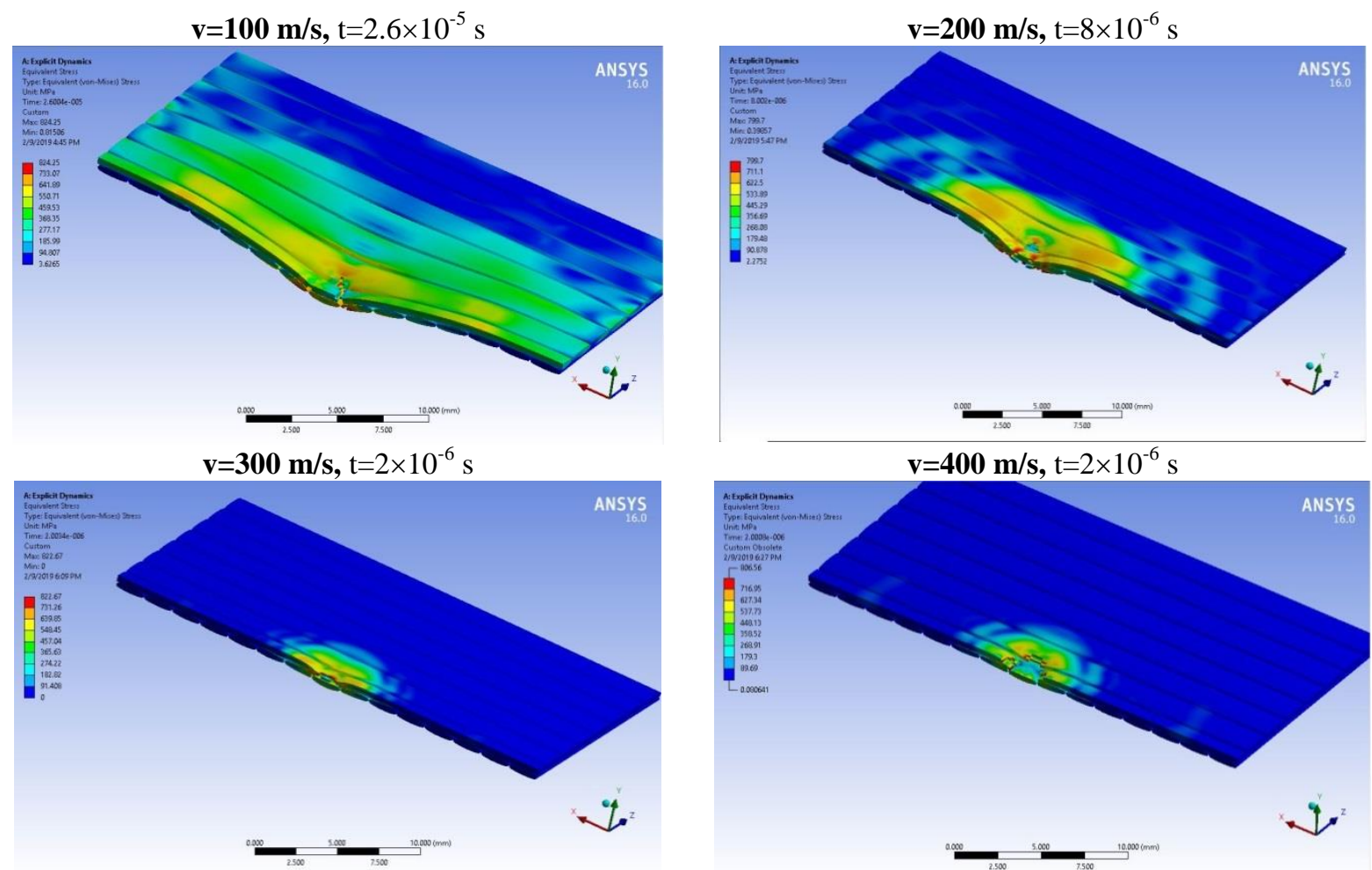

Fig. 9. Stressed areas and broken yarns (see Table 8)
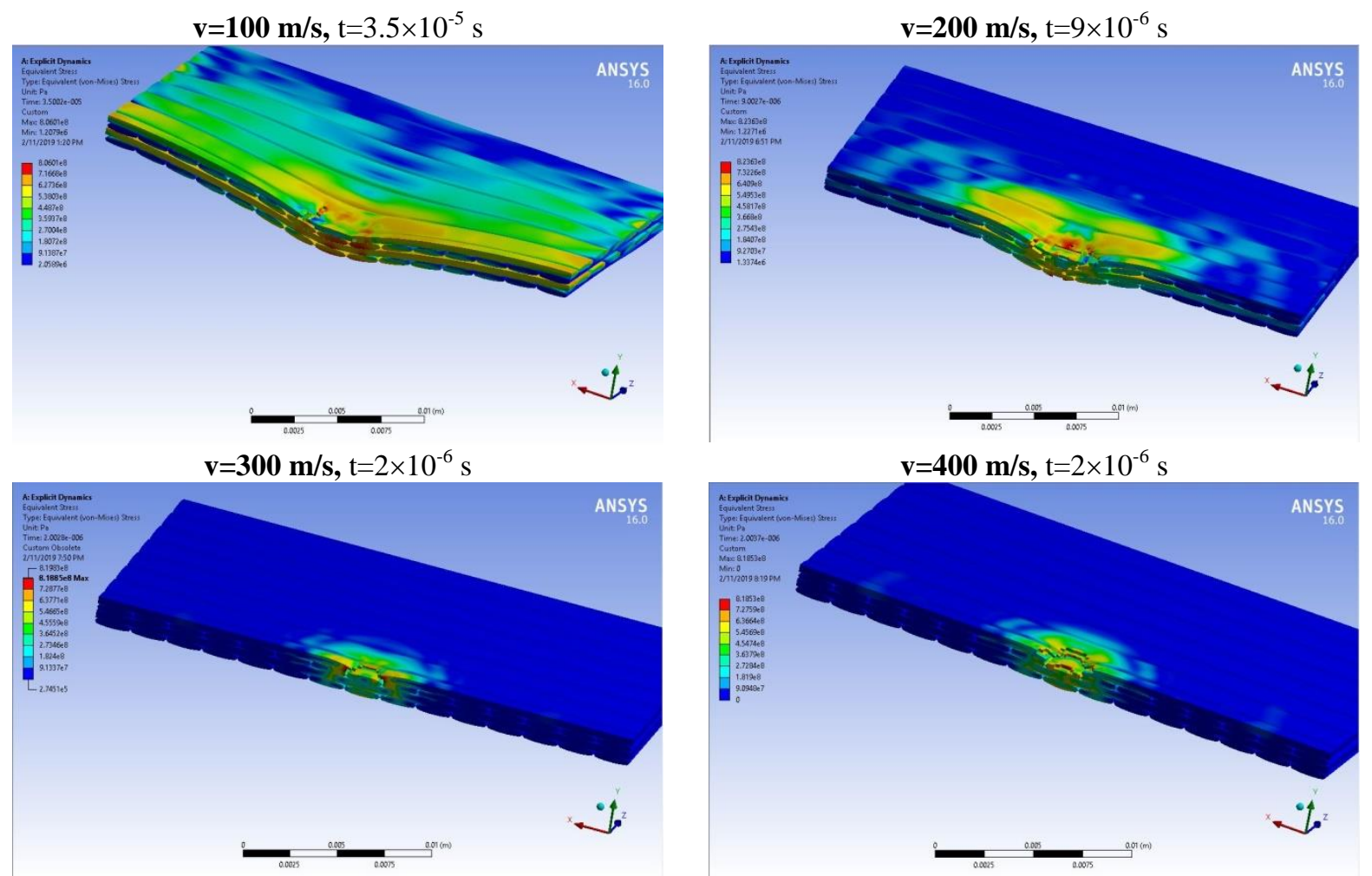

Fig. 11. Stress distribution for package with four layer

The speed and acceleration graphical survey of the projectile top gives information about the moments of yarn(s) breakage (sudden acceleration jumps or local speed decreases), and on the speed graphs, the residual velocity of the projectile can be identified (see Fig. 12).
From Table 10, it can be noticed that for lower velocities, the residual velocity has a lower percentage of the impact velocity, but at high speeds, for this package, the reduction of the residual velocity from the impact velocity is even lower $\left(2.7 \%\right.$ at $\mathrm{v}_{0}=300 \mathrm{~m} / \mathrm{s}$ and only $1.75 \%$ at $\left.\mathrm{v}_{0}=400 \mathrm{~m} / \mathrm{s}\right)$. 

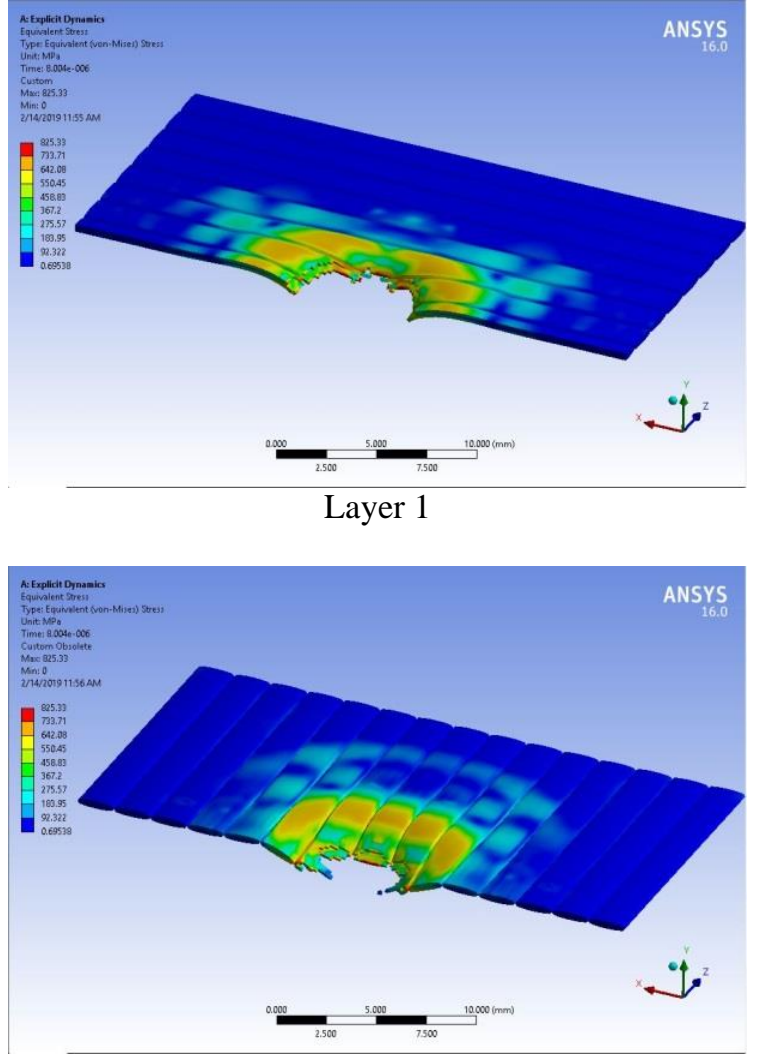

Layer 2

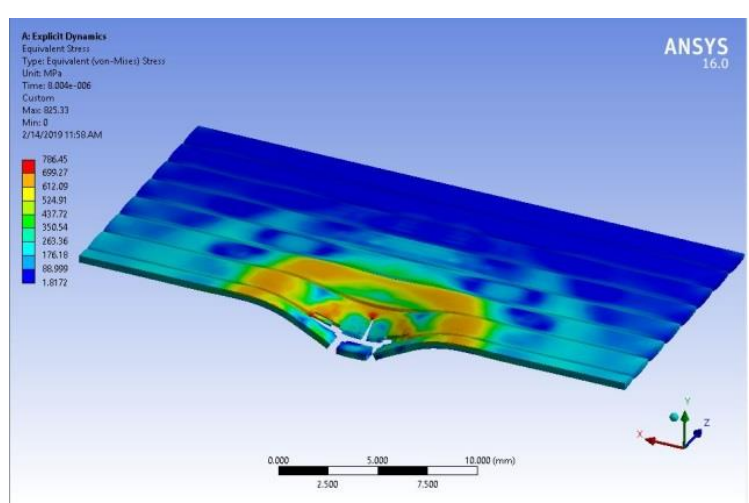

Layer 3

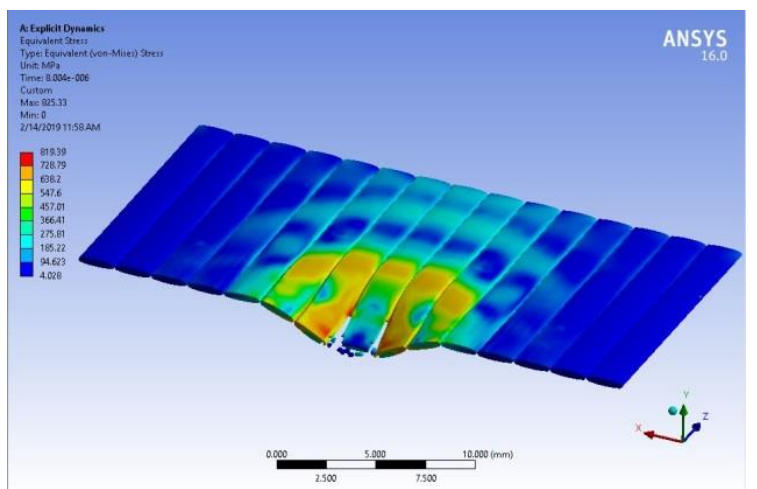

Layer 4

Fig. 13. View of the layer face, at $t=8 \times 10^{-6} \mathrm{~s}$, impact velocity $400 \mathrm{~m} / \mathrm{s}$ (other layers are set as transparent)

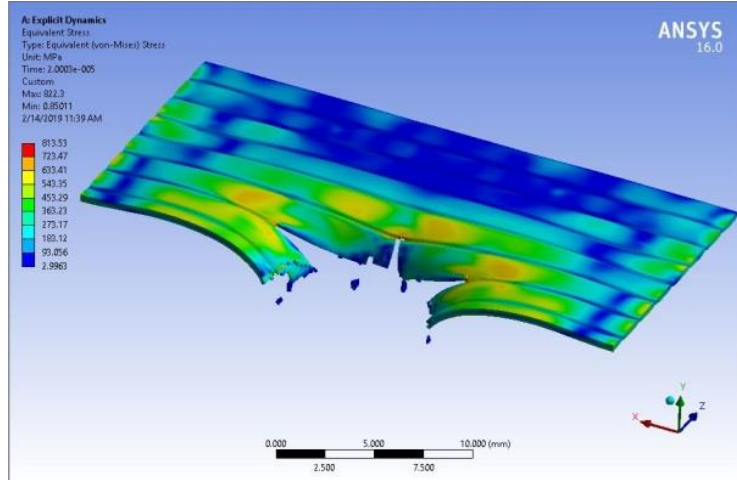

Layer 1

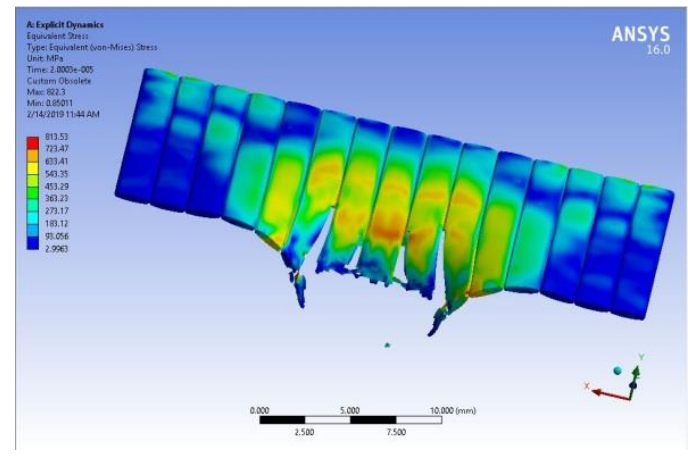

Layer 2

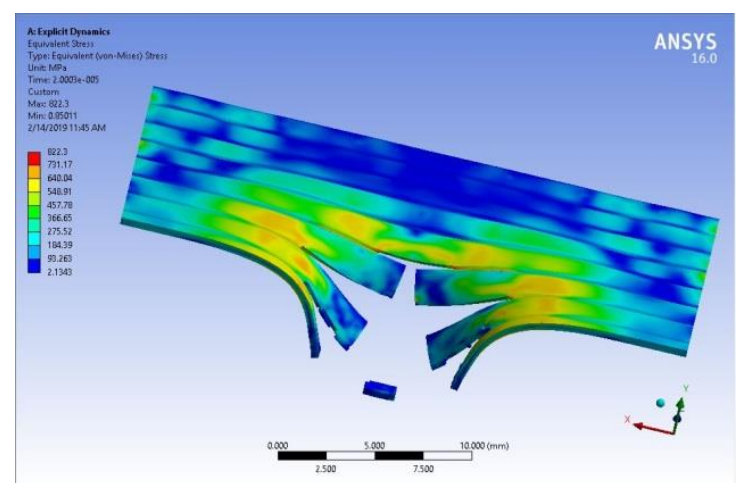

Layer 3

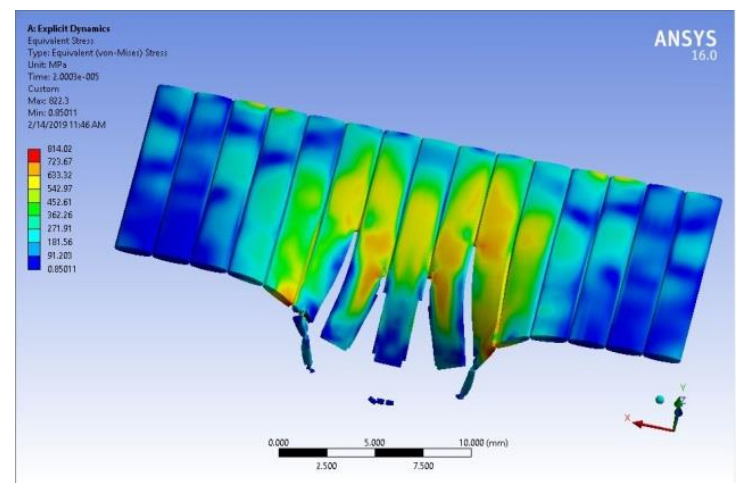

Layer 4

Fig. 14. View of the layer back, at $=2 \times 10^{-5} \mathrm{~s}$, impact velocity $400 \mathrm{~m} / \mathrm{s}$ (other layers are set as transparent) 
The simulation allows for a rapid evaluation of the solution that offers protection, meaning the projectile either penetrates it, or it is arrested). With better resources, the number of layers can be increased until the projectile is captured in the package without damaging the last layers, i.e. up to a residual velocity $v_{\text {residual }}=0 \mathrm{~m} / \mathrm{s}$. A simulation for this purpose was done by Pîrvu [2], but considering the homogeneous and isotropic layers. Even with this simplification of the fabric layer, by realistically modeling its equivalent mechanical properties, the author has obtained the number of layers needed for arresting a similar projectile having $400 \mathrm{~m} / \mathrm{s}$.

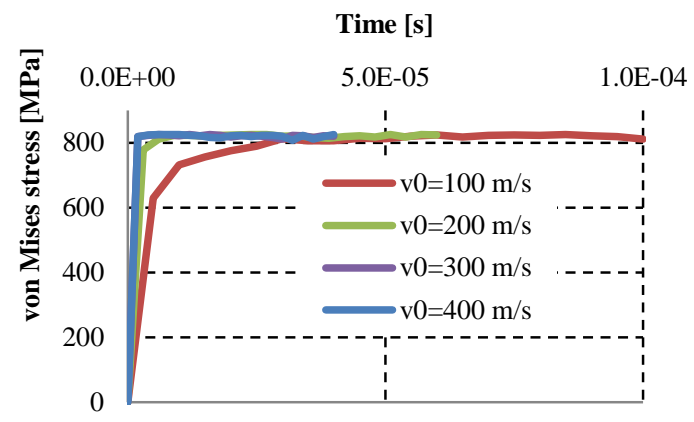

a) Maximum value of von Mises stress

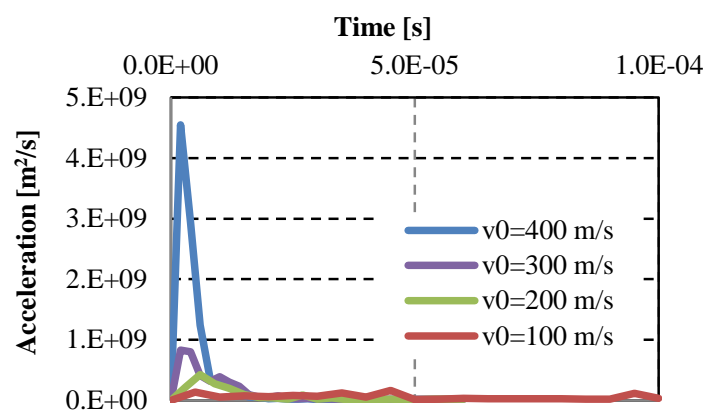

b) Accelaration of the projectile top point Time [s]

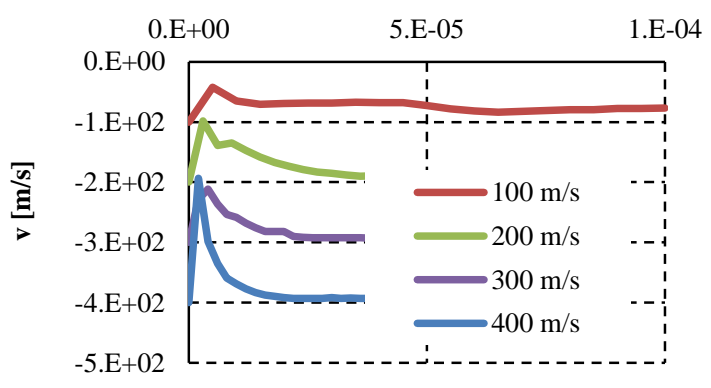

c) Velocityof the projectile top point

Fig. 12. Characteristics for four layer fabrics

Table 10. Analysis for the impact on 4 layers

\begin{tabular}{|l|c|c|c|c|}
\hline Case & $\mathbf{1}$ & $\mathbf{2}$ & $\mathbf{3}$ & $\mathbf{4}$ \\
\hline $\begin{array}{l}\text { Impact velocity, } \\
{[\mathrm{m} / \mathrm{s}]}\end{array}$ & 100 & 200 & 300 & 400 \\
\hline $\begin{array}{l}\text { Residual velocity } \\
{[\mathrm{m} / \mathrm{s}]}\end{array}$ & 77.06 & 190 & 292 & 393 \\
{$[\%]$} & 77.06 & 95 & 97.3 & 98.25 \\
\hline
\end{tabular}

In Figures 13 and 14, the yarn fragments that are completely detached are not visible.
The model presented here has layers made up of unidirectional wires $\left(0^{\circ}, 90^{\circ}\right)$, so the simulation is closer to reality and the deterioration process is expected to be realistic.

\section{CONCLUSIONS}

This paper presented a particular model of the target and projectile, taking into account constitutive models for the involved materials. It also discussed the influence of impact velocity and number of layers on residual velocity and acceleration of the projectile during the impact. The simulations tracked the behavior of the ballistic protection panels under the action of the $9 \mathrm{~mm}$ FMJ bullet, for packages of 1, 2 and 4 layers of unidirectional yarns.

The authors validated the results obtained from the impact simulations, obtaining similar results for the number of main and secondary yarns involved in impact destruction with those from ballistic tests performed by [2], the mechanical properties of the yarn were taken from the literature and product catalog of Teijin Aramid.

Performing simulations, in a realistic way, of impact processes reveal a multitude of issues, due to large displacements, high strain rates, cracks, erosion, nonlinearity aspects of materials bearing the impact. The use of dedicated softwares to model the behavior of materials, based on their particularities, highlights more reliable solutions with the significant reduction of experimental research and, therefore, the design costs [12].

The main advantage of such an approach is that, in the development phase of any product (experimental model, prototype), it is easy to obtain data in a short time and at no extra cost by simulation. Costs and time are reduced for a protection product by combining the experimentally obtained information with those obtained by numerical simulation in order to design and optimize the product.

\section{ACKNOWLEGMENT}

This paper was supported by a grant of the Romanian Ministery of Research and Innovation, CCCDI-UEFISCDI, project no. PN-III-P1-1.2PCCCDI-2017-0404/31PCCDI/2018, within PNCDI III and by Doctorale School for Mechanical and Industrial Engineering of "Dunarea de Jos" University of Galati.

\section{REFERENCES}

1. Safta I., 2011, Contribuţii la studiul teoretic şi experimental al mijloacelor individuale de protecţie balistică, $\mathrm{PhD}$ thesis, Academia Tehnică Militară, Bucharest.

2. Pirvu C., 2015, Contributions on numerical and experimental study of ballistic pakages made of aramif fibers (in Romanian), $\mathrm{PhD}$ thesis, „Dunarea de Jos" University, Galati, Romania. 
3. Yang L., Yan Y., Kuang N., 2013, Experimental and numerical investigation of aramid fibre reinforced laminates subjected to low velocity impact, Polymer Testing, 32, pp. 1163-1173.

4. Rajput M. S., Bhuary M. K., Gupta A., 2017, Finite element simulation of impact on PASGT army helmet, Procedia Engineering, 173, pp. 251258.

5. Sockalingam S., Gillespie Jr. J. W., Keefe M., 2015, Dynamic modeling of Kevlar KM2 single fiber subjected to transverse impact, International Journal of Solids and Structures, 67-68, pp. 297310.

6. Nilakantan G., Keefe M., Bogetti T. A., Adkinson R., Gillespie Jr. J. W., 2010, On the finite element analysis of woven fabric impact using multiscale modeling techniques, International Journal of Solids and Structures,47, pp. 2300-2315.

7. Grujicic M., Bell W. C., Glomski P. S., Yen C-F., Pandurangan B., 2011, Cheeseman B. A., Multilength scale computational derivation of kevlar yarn-level material model, Journal of Materials Science, 46, pp. 4787-4802.

8. Tan V. B. C., Shim V. P. W., Zeng X. S., Modelling crimp in woven fabrics subjected to ballistic impact, International Journal of Impact Engineering 32 (2005) pp. 561-574

9. Kulkarni S. G., Gao X.-L., Horne S. E., Zheng J. Q., David N. V., 2013, Ballistic helmets - Their design, materials, and performance against traumatic brain injury, Composite Structures, 101 pp. 313-331.

10. Ning H., Pillay S., Balaji K. T., Vaidy U. K., 2017, Design and manufacturing of long fiber thermoplastic composite helmet insert, Composite Structures, 168, pp. 792-797.

11. Bucur F., 2015, Contribuţii la îmbunătăţirea factorului de protecţie a blindajelor pentru autovehicule militare, $\mathrm{PhD}$ thesis, Academia Tehnica Militară, Bucharest.

12. *** Opportunities in Protection Materials Science and Technology for Future Army Applications, 2011, ISBN 978-0-309-21285-4.

13. Abrate S., Impact engineering of composite structures, Springer, New York, 2011

14. Carrillo J. G., Gamboa R. A., Flores-Johnson E. A., Gonzalez-Chi P. I., 2012, Ballistic performance of thermoplastic composite laminates made from aramid woven fabric and polypropylene matrix, Polymer Testing, 31, pp. 512-519.

15. Peroni L., Scapin M., Fichera C., Manes A., Giglio M., 2012, Mechanical properties at high strain-rate of lead core and brass jacket of a nato $7.62 \mathrm{~mm}$ ball bullet, EPJ Web of Conferences 26, 01060.

16. Grujicic M., Snipes J., Avuthu S. R. V., Yen C.-F., Cheeseman B., 2016, Derivation of the material models for ultra-high molecular-weight polyethylene fiber-reinforced armor-grade composites with different architectures, Engineering Computations, 33(3), pp. 926-956.

17. Tan P., 2014, Ballistic protection performance of curved armor systems with or without debondings/delaminations, Materials and Design, 64, pp. 25-34.

18. Tan P., Lee B., Tsangalis C., 2010, Finite element analysis of sandwich panels subjected to shock tube blast loadings, Journal of Sandwich Structures and Materials, 13(3), pp. 263-278.

19. Sockalingam S., Gillespie Jr. J. W., Keef M., 2015, Dynamic modeling of Kevlar KM2 single fiber subjected to transverse impact, International Journal of Solids and Structures, 67-68, pp. 297310

20. Grujicic M., Hariharan A. B., Yen C.-F., Cheeseman B. A., Wang Y., Miao Y., Zheng J.Q., 2012, Fiber-Level modeling of dynamic strength of Kevlar KM2 ballistic fabric, ASM International Journal of Materials Engineering and Performance, 21, pp. 1107-1119.

21. Dejl R., Grégr J., Maršálková M., Krupincová G., 2010, Evaluation of Ballistic Suitability of Textiles Possibility of Measurements and Evaluation of Ballistic Suitability of Textiles, 7th International Conference, TEXSCI, September 6-8, Liberec, Czech Republic.

22. Endruweit A., Zeng X., Matveev M., Long A. C., 2018, Effect of yarn cross-sectional shape on resin flow through inter-yarn gaps in textile reinforcements., Composites Part A. Applied Science and Manufacturing, 104, pp. 139-150.

23. Potluri P, Sagar T. V., 2008, Compaction modelling of textile preforms for composite structures, Composite Structures, 86(1-3), pp.17785.

24. Wong C. C., Long A. C., Sherburn M., Robitaille F., Harrison P., Rudd C. D., 2006, Comparisons of novel and efficient approaches for permeability prediction based on the fabric architecture. Composites Part A. Applied Science and Manufacturing, 37(6), pp. 847-857.

25. *** Teijin-Aramid Ballistics-Material-HandbookEnglish1

26. Bhatnagar A, Lightweight ballistic composites, CRC Press, Boca Raton, 2006

27. Jaiswal A., Structural Mechanics https://support.ansys.com/staticassets/ANSYS/Con ference/Palm\%20Beach/downloads/ANSYS\%20E xplicit\%20Dynamics\%20-

\%20Ashish\%20Jaiswal.pdf, avaible on line 12.04.2019.

28. Nilakantan G., Nutt S., Effects of Clamping Design on the ballistic impact response of soft body armor, Composite Structures, 108, pp. 137150, 2014.

29. Năstasescu V., 2012, Metoda SPH (Smoothed Particle Hydrodynamics), Editura Academiei Forţelor Terestre "Nicolae Bălcescu", Sibiu.

30. Kennedy J. M., 2013, Introductory Examples Manual for LS-DYNA®Users, Livermore Software Technology Corporation (LSTC). 